\title{
Técnicas de Geoprocessamento e Sensoriamento Remoto Aplicadas na Identificação de Conflitos do Uso da Terra em Seropédica-RJ
}

\author{
Kaio Allan Cruz Gasparini ${ }^{1}$, Gustavo Bastos Lyra², \\ Márcio Rocha Francelino ${ }^{3}$, Rafael Coll Delgado², \\ José Francisco de Oliveira Junior ${ }^{3}$, Alexandro Gomes Facco ${ }^{4}$

\begin{abstract}
${ }^{1}$ Departamento de Engenharia Florestal, Universidade Federal do Espírito Santo - UFES, Vitória/ES, Brasil ${ }^{2}$ Departamento de Ciências Ambientais, Universidade Federal Rural do Rio de Janeiro - UFRRJ, Seropédica/RJ, Brasil

${ }^{3}$ Departamento de Silvicultura, Universidade Federal Rural do Rio de Janeiro - UFRRJ, Seropédica/RJ, Brasil

${ }^{4}$ Departamento de Ciências Agrárias e Biológicas, Universidade Federal do Espírito Santo - UFES, Vitória/ES, Brasil
\end{abstract}

\section{RESUMO}

Este trabalho avaliou o uso e a cobertura da terra, e comparou os dados obtidos com aqueles das Áreas de Preservação Permanente (APPs), para identificar conflitos do uso da terra no município de Seropédica-RJ. Utilizaram-se duas cenas do satélite CBERS2 e a classificação supervisionada com o método da mínima distância. As APPs foram delimitadas com o auxílio de geotecnologias, baseando-se na legislação ambiental (Lei n. ${ }^{\circ}$ 12.651/2012) (Brasil, 2012). Utilizou-se no mapeamento das APPs um Modelo Digital de Elevação (1:25.000) e, para a rede de drenagem, cartas planialtimétricas (1:10.000). Identificaram-se $40,02 \mathrm{~km}^{2}$ de APPs, o que correspondeu a $15,01 \%$ do município. A APP do rio Guandu apresentou maior área $(7,23 \%)$ e lagos urbanos, a menor $(0,04 \%)$. O município não apresentou APPs de declividade $\left(<40^{\circ}\right)$ e de topo de morro (declividade $<25^{\circ} \mathrm{com}$ altitude $<100$ ). Em relação aos conflitos do uso da terra, o solo exposto correspondeu a 58,1\%, pastagem a $21,7 \%$, areia/mineração a $7,8 \%$ e área urbana a 3,9\%. Os resultados obtidos indicam eficiência dessas geotecnologias na gestão municipal.

Palavras-chave: geoprocessamento, Área de Preservação Permanente, Rio Guandu.

\section{Geoprocessing Techniques and Remote Sensing Applied to the Identification of Land Use Conflicts in Seropédica, RJ}

\begin{abstract}
In this study, we evaluated the use and cover of land and compared data with the Permanent Preservation Areas (PPAs) to identify conflicts of land use in the municipality of Seropédica, Rio de Janeiro state, Brazil. We used two CBERS2 satellite scenes and supervised classification by the method of minimum distance. PPAs were defined with the aid of geotecnhology based on the Brazilian environmental legislation (law ${ }^{\circ}$. 12.651/2012) (Brasil, 2012). PPA mapping was performed on a Digital Elevation Model (1:25.000) and planialtimetric mapping (1:10.000) was used for the drainage network. We identified $40.02 \mathrm{~km}^{2}$ of PPAs, corresponding to $15.01 \%$ of the municipality studied. The Guandu River PPA was the largest $(7.23 \%)$, while the urban lakes PPA was the smallest $(0.04 \%)$. No PPAs of slope $\left(<40^{\circ}\right)$ or hill top (slope $<25^{\circ}$ with altitude $<100 \mathrm{~m}$ ) were identified in the municipality. The following data were found regarding the conflicts of land use: $58.1 \%$ exposed soil, $21.7 \%$ grassland, $7.8 \%$ sand/mining, and $3.9 \%$ urban area. Results indicate the efficiency of geotecnhology in municipal management.
\end{abstract}

Keywords: geoprocessing, Permanent Preservation Areas, Guandu River. 


\section{INTRODUÇÃO}

O município de Seropédica situa-se na mesorregião metropolitana do Estado do Rio de Janeiro, na região da Baixada de Sepetiba. A maioria dos rios que compõem as bacias hidrográficas dessa região, entre as quais a Bacia do Rio Guandu, teve seus cursos originais modificados pela ação do homem. Entre as alterações, destacam-se os processos de retificação e dragagem dos leitos, e canalização e união de rios por valões (Rio de Janeiro, 2001).

Durante décadas, a estratégia da Engenharia Fluvial e Hidráulica se baseou na retificação de leitos dos rios e córregos, para que suas vazões fossem dirigidas para jusante, pela menor distância e com a maior velocidade de escoamento (Binder, 1998). Os objetivos dessa estratégia foram disponibilizar áreas para a agricultura e a urbanização, e minimizar os efeitos locais das cheias. Contudo, a realização dessas obras teve impactos ambientais graves, não avaliados previamente, como, por exemplo, a redução da biodiversidade (Binder, 1998). Em virtude dessas ações, diversas feições originais das bacias da região não existem atualmente, sendo necessário, para a preservação do remanescente ambiental, o conhecimento das áreas protegidas pela legislação e a definição atual do uso e da ocupação do solo na Bacia, para que se possam avaliar os conflitos do uso do solo e, assim, definir as áreas que precisam ter seus atributos ambientais preservados.

$\mathrm{Na}$ tentativa de minimizar o desmatamento, foi elaborado o Código Florestal no ano de 1965 (Lei n. ${ }^{\circ}$ 4.771/1965) (Brasil, 1965). Essa foi uma das principais leis ambientais do Brasil para a conservação do patrimônio ambiental natural, não somente em função da proteção de áreas com vegetação nativa como também para manutenção do abrigo de fauna e flora; também é importante por estabelecer regras de proteção dos cursos d'água, nascentes, lagos, lagoas e reservatórios naturais e artificiais, e proteção do solo contra erosão nas encostas, topos de montanhas, morros e chapadas (Lima, 2008). Contudo, em maio de 2012, foi instituída a Lei n. ${ }^{\circ}$ 12.651, na qual se altera a Lei n. ${ }^{\circ} 4.771 / 1965$. O artigo $4 .^{\circ}$ da Lei 12.651/2012 apresenta as Áreas de Preservação Permanente (APP) e suas devidas formas de demarcação, que se distinguem em alguns pontos em relação ao Código Florestal de 1965 (Brasil, 2012). Essas áreas atuam, principalmente, na conservação do regime hidrológico e causam a estabilização das linhas de drenagem natural e suas margens. Em paisagens agrícolas, as áreas protegidas funcionam como filtro biológico nos processos de erosão laminar, lixiviação, deriva e fluxo lateral de agroquímicos, e ainda possuem a função de isolamento e quebra-ventos para essas áreas (Valente \& Gomes, 2005).

Embora o Brasil possua a legislação ambiental rigorosa, há falta de fiscalização, em razão, muitas vezes, da grande extensão das áreas de estudo e das restrições de informações sobre as mesmas, além do custo de tempo e pessoal para realização desses estudos (Nascimento et al., 2005). Nessas condições, técnicas de Sistema de Informação Geográfica (SIG) e Sensoriamento Remoto (SR) auxiliam na delimitação de extensas áreas de potencial preservação, sendo capazes de expressar eficientemente conceitos de expressão territorial, tais como as unidades potenciais de uso da terra, as zonas de influência de determinado parâmetro, as áreas críticas, os centros dinâmicos de poder e as áreas de preservação permanente, entre outros (Xavier-da-Silva, 2001). Para o manuseio e a análise dos dados provenientes de sensores remotos, os aplicativos mais usados atualmente são os de processamento digital de imagens e os denominados Sistemas de Informações Geográficas (SIGs). Esses aplicativos são capazes de armazenar, analisar e localizar espacialmente dados já analisados e tratados (Piroli et al., 2002).

Técnicas de geoprocessamento e sensoriamento remoto aplicadas a análises ambientais têm se mostrado eficientes, e vários trabalhos consideram essa abordagem (Caldas, 2006; Salamene, 2007). O presente trabalho tem por objetivo identificar regiões de conflito do uso da terra com base na legislação ambiental (Áreas de Preservação Ambiental) e no uso e na ocupação da terra do município de SeropédicaRJ, com auxílio de técnicas de geoprocessamento e sensoriamento remoto.

\section{MATERIAL E MÉTODOS}

O estudo foi desenvolvido para o município de Seropédica-RJ (Figura 1), com área de aproximadamente 266,55 $\mathrm{km}^{2}$. Embora 


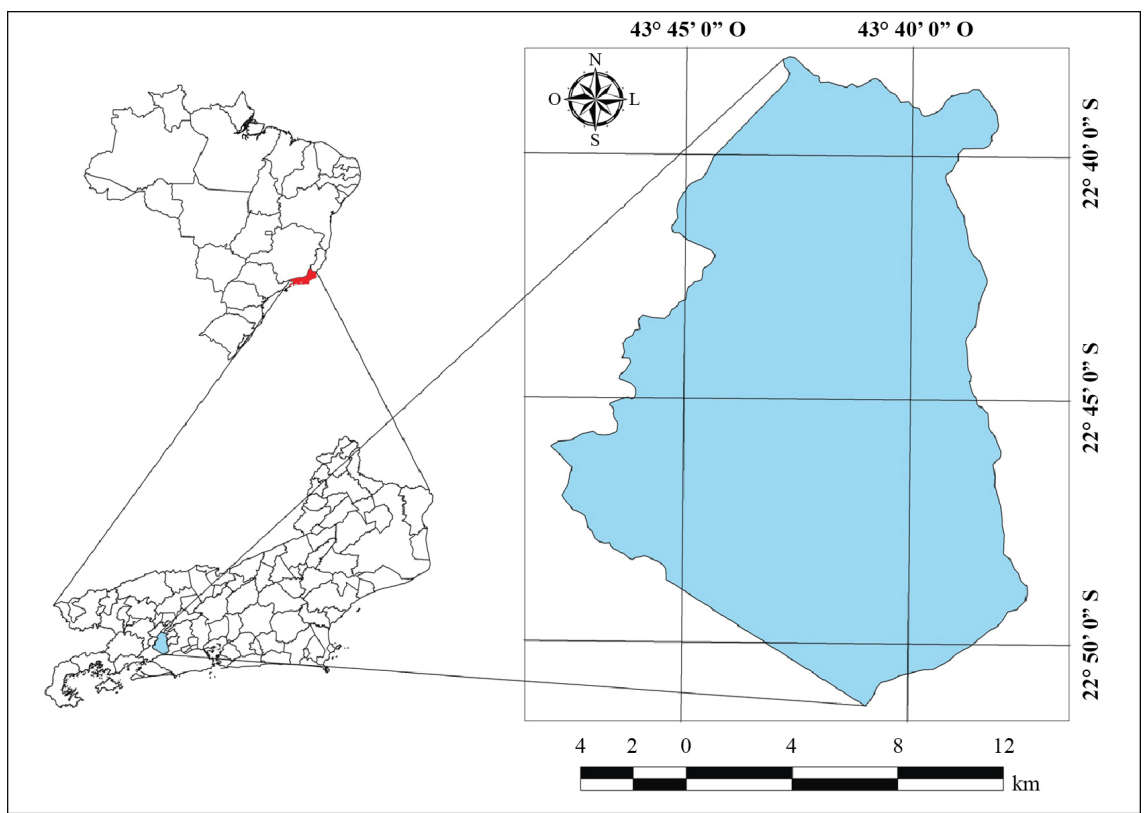

Figura 1. Localização geográfica do município de Seropédica-RJ.

Figure 1. Seropédica, RJ Municipal Location.

considerado politicamente como integrante da Região Metropolitana do Rio de Janeiro (RMRJ), geograficamente está situado em uma área da planície costeira fluminense, denominada Baixada de Sepetiba (Jaccoud, 2006). Limitada ao sul pelo Oceano Atlântico, essa baixada possui como limites interiores a Serra do Mar a oeste e noroeste, o Maciço da Pedra Branca a leste, a Serra da Mantiqueira a nordeste e, a norte e nordeste, uma sucessão de morros de pequena altitude, que se incorporam à chamada paisagem do Mar de Morros (Jaccoud, 2006).

Para o mapeamento das áreas (areia/mineração, água, área urbana, mata, pastagem e solo exposto), foram utilizadas duas imagens do satélite CBERS2 da câmera CCD (Couple Charge Device); a câmera CCD possui faixas espectrais (cinco bandas) e fornece imagens de uma faixa de $113 \mathrm{~km}$ de largura a uma resolução de $20 \mathrm{~m}$. As duas cenas correspondem à órbita 151 e aos pontos 125 e 126 para o dia $14 / 02 / 2008$, sendo que as mesmas foram obtidas já georreferenciadas e estão disponíveis em <http:// www.siscom.ibama.gov.br/mapoteca_img/cbers_ georef_html/CBERS-Georreferenciado.html>.

Antes da classificação supervisionada, foi necessário fazer o mosaico das duas cenas e a coleta de assinaturas, como verdade de campo (polígonos de mata e área urbana), adquiridas por meio do acesso ao link <http://www.mapas.sosma.org.br>.

A utilização de apenas duas classes observacionais (mata e área urbana) restringiu-se pela falta de informações adicionais (dados de referência) da região classificada, como, por exemplo: fotos aéreas, mapas e ortofotos, entre outros.

Foi utilizado o método de classificação supervisionada por mínima distância, em que se toma como referência, para cada classe, um ponto no espaço multidimensional definido pela média estatística de cada banda espectral considerada. O algoritmo associa cada pixel desconhecido à classe cuja média está mais próxima. Cada pixel dentro e fora das áreas de treinamento é avaliado e assinalado à classe a qual este tem a maior probabilidade de pertencer.

Para a avaliação da precisão da imagem final produzida no processo de classificação supervisionada, adotou-se o índice Kappa (Equação 1). Esse índice é um dos principais métodos utilizados para avaliar a concordância entre a verdade terrestre e o mapa temático. A grande vantagem do uso da estatística Kappa é que, no cálculo do coeficiente Kappa, incluem-se todos os elementos da 
matriz de erro. A estatística Kappa varia de 0 a 1 . Um valor de Kappa igual a zero sugere que a classificação não é melhor do que uma classificação aleatória dos pixels. Um valor igual a um sugere um processo de classificação altamente eficiente (Moreira, 2001).

$$
\mathrm{K}=\frac{\mathrm{N} \sum_{\mathrm{i}=1}^{\mathrm{r}} \mathrm{X}_{\mathrm{ii}}-\sum_{\mathrm{i}=1}^{\mathrm{r}}\left(\mathrm{X}_{\mathrm{i}+}{ }^{*} \mathrm{X}_{+\mathrm{i}}\right)}{\mathrm{N}^{2}-\sum_{\mathrm{i}=1}^{\mathrm{r}}\left(\mathrm{X}_{\mathrm{i}+}{ }^{*} \mathrm{X}_{+\mathrm{i}}\right)}
$$

em que: $\mathrm{K}=$ índice de exatidão Kappa; $\mathrm{r}=$ número de linhas da matriz; $\mathrm{X}_{\mathrm{ii}}=$ número de observações na linha i e coluna $\mathrm{i}$; $\mathrm{X}_{\mathrm{i}+}$ e $\mathrm{X}_{+\mathrm{i}}=$ totais marginais da linha i e coluna i, respectivamente; $\mathrm{N}=$ número total de observações.

Para o processamento dos dados, foram utilizados os softwares ArcGIS 9.3 e ERDAS IMAGINE 2010. Empregou-se o ArcGIS 9.3 no trabalho de dados vetoriais, banco de dados e mapas. Já o ERDAS IMAGINE 2010 foi utilizado nas seguintes etapas: calibração radiométrica, refletância das bandas e classificação supervisionada. O software ENVI $^{\circ}$ versão 4.5 foi utilizado para o georreferenciamento e, em seguida, o mosaico, a partir das cartas digitalizadas. Após o processo de mosaico das cartas, iniciou-se a vetorização das linhas de drenagem, realizada através do módulo de edição de feições do ArcGIS* 9.3.

Os dados de relevo usados na definição das Áreas de Preservação Permanente foram obtidos do site do Instituto Brasileiro de Geografia e Estatística (IBGE, 2011), disponíveis como Modelos Digitais de Elevação (MDE), na escala 1:25.000. Os MDEs encontravam-se no formato geoTIFF com resolução espacial de $20 \mathrm{~m}$, projeção cartográfica Universal Transversal de Mercator (UTM) e Datum horizontal WGS-1984, zona 23 S. Os dados de hidrografia foram obtidos da vetorização de cartas digitalizadas, cedidas pela Fundação Centro Estadual de Estatística, Pesquisas e Formação de Servidores Públicos do Rio de Janeiro (CEPERJ), antiga Fundação CIDE. Essas cartas foram elaboradas através de um levantamento da década de 1970, realizado pela antiga Fundação para o Desenvolvimento da Região Metropolitana (FUNDREM), na escala 1:10.000, com projeção UTM e Datum Córrego Alegre (formato TIFFTagged Image File Format).

A partir do MDE, foi delimitada uma área retangular (máscara), que abrangia o município de Seropédica. Essa máscara foi necessária para reamostrar o MDE da resolução espacial de $20 \mathrm{~m}$, para uma resolução espacial de $5 \mathrm{~m}$ (Equação 2), para que a escala do MDE estivesse compatível com a escala dos dados de hidrografia 1:10.000 (Peluzio et al., 2010). A reamostragem foi feita transformando o MDE de $20 \mathrm{~m}$ para arquivo shapefile ( $\left.{ }^{*} . \mathrm{shp}\right) \mathrm{de}$ pontos e utilizando o interpolador Topo to Raster do ArcGIS 9.3, em que se gerou o MDE com a nova resolução (5 m).

$R h=0,0002 \times D E S$

em que: $\mathrm{Rh}(\mathrm{m})$ = resolução espacial; $\mathrm{DES}=$ denominador de escala.

As APPs foram delimitadas segundo a Lei 12.651 de maio de 2012 (Brasil, 2012). As APPs relacionadas à rede hidrográfica foram demarcadas segundo o método usado por Peluzio et al. (2010), no qual se utilizou a ferramenta Buffer do software ArcGis 9.3. Para demarcar as APPs das nascentes, criou-se um buffer de $50 \mathrm{~m}$ de distância, conforme considerado por Ribeiro et al. (2005), Peluzio et al. (2010) e Soares et al. (2011). Para as APPs de hidrografia, separou-se a hidrografia em diferentes camadas, conforme a Tabela 1.

Essas distâncias da margem da rede hidrográfica foram definidas conforme a Lei 12.651/12 (Brasil,

Tabela 1. APPs de hidrografia do município de Seropédica.

Table 1. APP's hydrography Seropédica Municipal.

$\begin{array}{cccc}\text { Feição } & \text { Restrição } & \text { Buffer (m) } & \text { Nome } \\ \text { Nascente } & - & 50 & \text { APP Nascentes } \\ \text { Cursos d'água } & \text { Largura até } 10 \mathrm{~m} & 30 & \text { APP Cursos Menores } \\ & \text { Entre } 10 \text { e } 50 \mathrm{~m} & 50 & \text { APP Cursos Maiores } \\ \text { Lagos } & \text { Urbano } & 30 & \text { APP Lagos Urbanos } \\ & \text { Rural } & 50 & \text { APP Lagos Rurais } \\ \text { Rio Guandu } & \text { Decreto n. }{ }^{\circ} 40.6270 / 07 & 500 & \text { APP Guandu }\end{array}$


2012). No caso do Rio Guandu, foi feito um buffer de $500 \mathrm{~m}$, conforme o Decreto n. ${ }^{\circ} 40.6270$ de 22 de março de 2007 (Rio de Janeiro, 2007).

Para delimitação de APPs de encostas, utilizou-se o método descrito por Peluzio et al. (2010), segundo o qual, através da ferramenta Slope do software ArcGis 9.3, determina-se a declividade do terreno. Segundo a Lei $12.651 / 12$, no Artigo $4 .^{\circ}$, Parágrafo V, são áreas de APP as encostas ou parte destas que possuir declividade superior a $45^{\circ}$, equivalente a $100 \%$ na linha de maior declive (Brasil, 2012). As APPs de topo de morro foram delimitadas conforme o método descrito por Peluzio et al. (2010). Segundo a Lei 12.651/12, no Artigo 4º Parágrafo X, são áreas de APPs de topos de morros as montanhas e serras com altura mínima de $100 \mathrm{~m}$ e, concomitantemente, possuírem inclinação média maior do que $25^{\circ}$; também as áreas acima da curva de nível correspondente a dois terços da altura mínima da elevação em relação à base, sendo essa base definida a partir do plano horizontal determinado por planície ou espelho d'água adjacente e, nos relevos ondulados, pela cota do ponto de cela mais próximo à elevação (Brasil, 2012). O processo de delimitação é descrito na Figura 2.

\section{RESULTADOS E DISCUSSÃO}

O município de Seropédica apresentou em seu relevo baixa amplitude da altitude (0-196 m). Na porção sul (S) do Município, o relevo mostrou as menores altitudes, associadas à pequena variação dessa feição do relevo. A partir da região central e do norte do Município, as altitudes apresentaram aumento significativo em comparação à porção $S$, sendo observados os maiores $(>120 \mathrm{~m})$ valores na região norte $(\mathrm{N})$. A porção oeste $(\mathrm{W})$ também teve altitudes entre as maiores do Município, decorrentes da região da Serra das Araras (Figura 3). Na Figura 4, o corte A-A' representou a variação da elevação de N para S. O transecto A-A' mostrou que o relevo possui elevações maiores na porção $\mathrm{N}$ do Município (em torno de $140 \mathrm{~m}$ ). O corte B-B' representou a variação de $\mathrm{W}$ para leste (E) e mostrou que, na região $\mathrm{W}$ do município, ocorrem as maiores altitudes (em torno de $160 \mathrm{~m}$ ).

Outra análise realizada neste estudo foi a hipsometria do município de Seropédica-RJ, para verificar qual a frequência (\%) de classes de altitude. A partir do mapa de hipsometria, obteve-se a frequência relativa da altitude (Figura 5). Observouse que a classe de 0-25 m compôs a maior parte do relevo do Município e representou $81,97 \%$ da área total, seguida da classe de $25-50 \mathrm{~m}$, com 9,35\%, e da classe de 50-100 m, com 5,80\%. As classes de menor frequência de ocorrência foram a de 100-150 m, que representou 2,48\%, e a classe de 150-200 m, que mesmo não se destacando na Figura 5 , mostrou apenas $0,41 \%$ de ocorrência no relevo. Com base na análise, na região de Seropédica-RJ, predominou relevo entre 0 e $100 \mathrm{~m}$ de altitude (planície) e poucas inclinações acentuadas (morros e colinas).

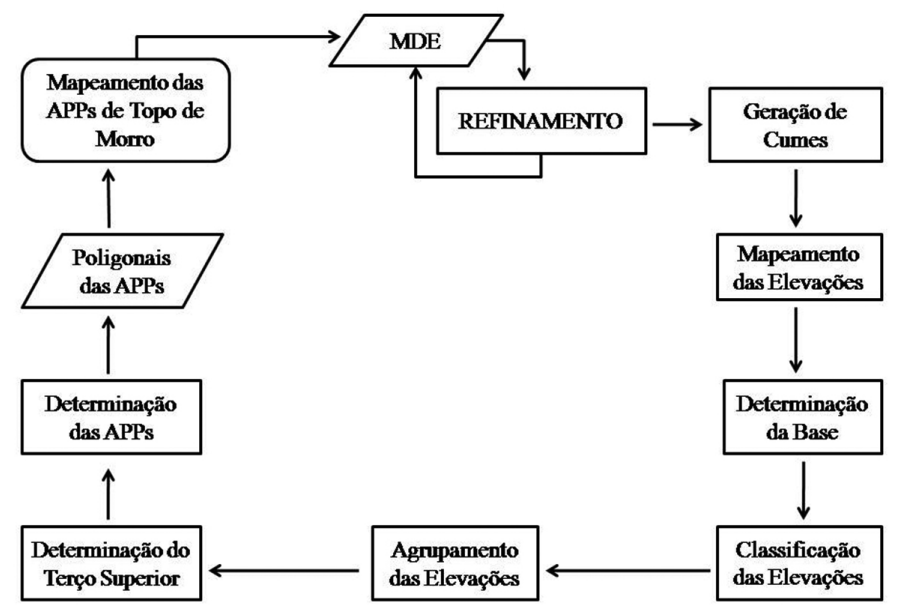

Figura 2. Fluxograma das etapas envolvidas no mapeamento das APPs de topo de morro em Seropédica-RJ. Figure 2. Fluxogram of APP's mapping steps involved at top hill in Seropédica, RJ. 


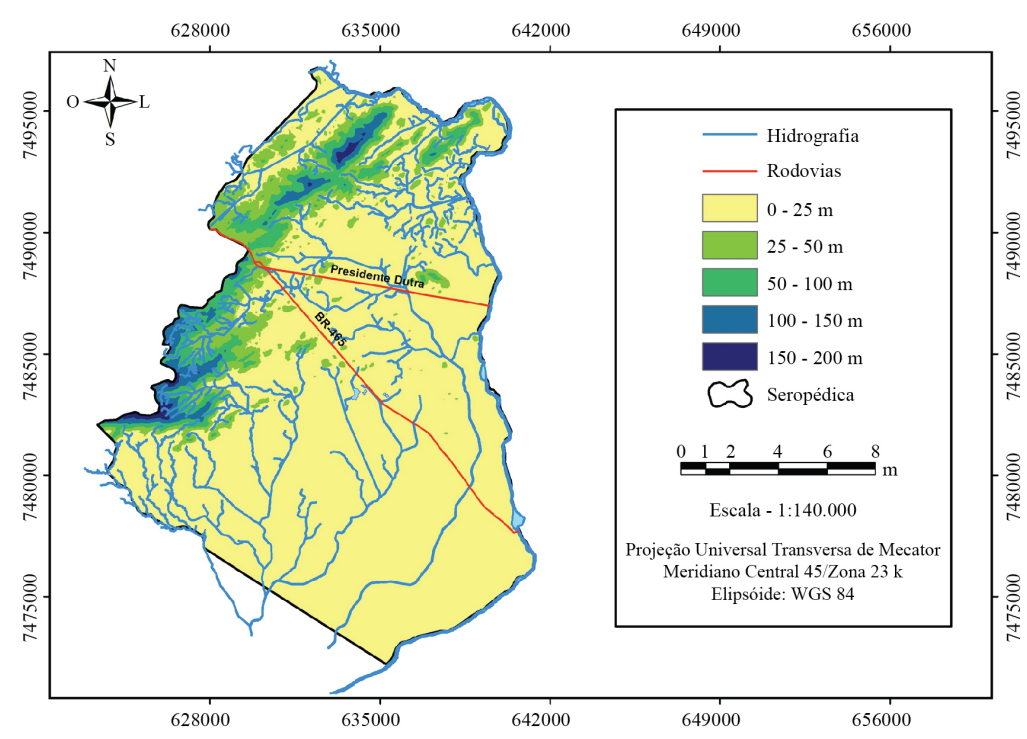

Figura 3. Hipsometria do município de Seropédica-RJ.

Figure 3. Hipsometry at Seropédica, RJ Municipal.
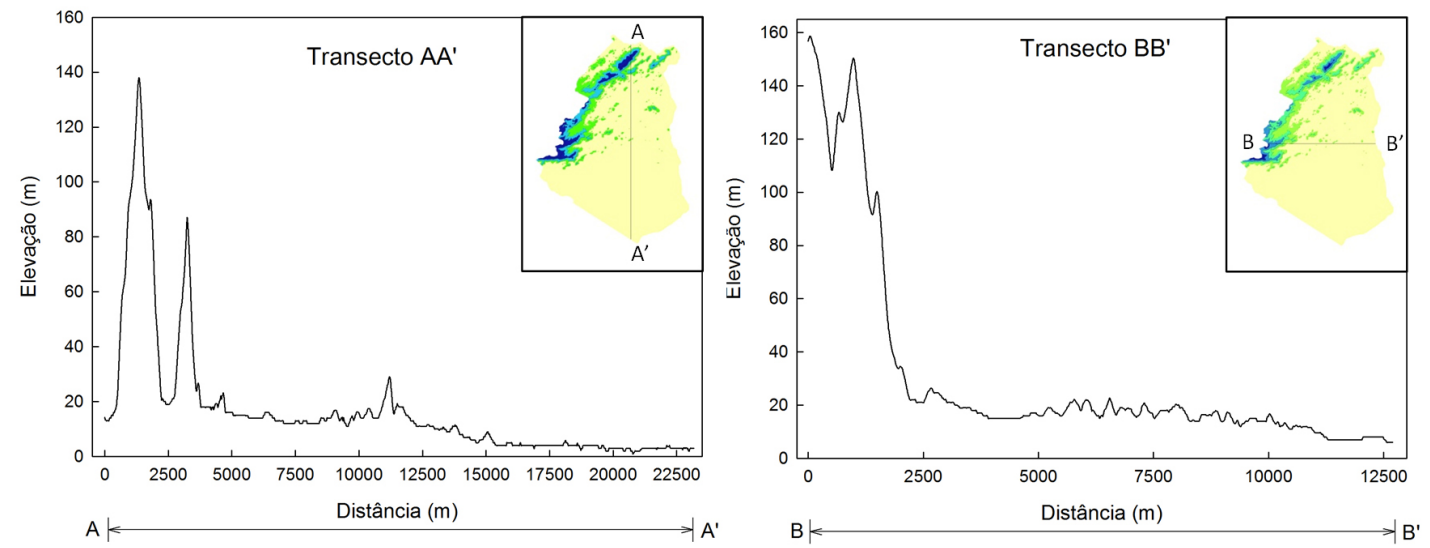

Figura 4. Variação do relevo representado por perfis topográficos.

Figure 4. Variation of the relief represented by topographic profiles.

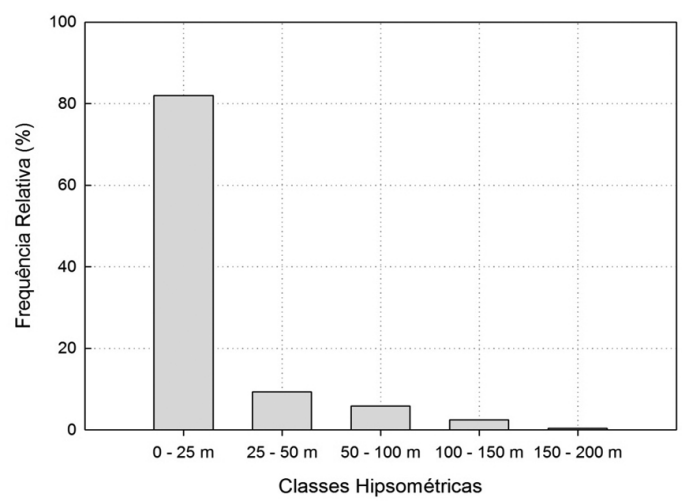

Figura 5. Distribuição da frequência relativa (\%) da elevação do município de Seropédica-RJ.

Figure 5. Relative frequency elevation (\%) distribution at Seropédica, RJ Municipal.
A hidrografia do município, como descrita na introdução, possui suas feições retificadas (Binder, 1998; Rio de Janeiro, 2001), como pode ser observado na Figura 3. Contudo, o relevo da região, por se tratar de uma baixada, apresentava originalmente rede hidrográfica com características meandrantes. Destaca-se, na hidrografia da região, o Rio Guandu e seus contribuintes.

A região de Seropédica-RJ apresentou relevo com declividades inferiores a $45^{\circ}$ de inclinação, o que é equivalente a 100\% (Figura 3); assim, não foram identificadas APPs de declividade no Município.

Quintero et al. (2008) realizaram estudo no município de Barra Mansa-RJ, onde foram 
amostrados pontos de GPS diferencial e, posteriormente, comparados aos MDEs em escalas diferentes, obtidos de mapeamentos da Prefeitura Municipal (escala 1:5.000), do IBGE (escala 1:50.000) e do SRTM (escala 1:100.000). Os resultados mostraram que apenas o MDE na escala 1:5.000 detectou as declividades acima de $45^{\circ}$.

Os resultados obtidos no presente trabalho mostraram que, na escala (1:25.000), não foi possível identificar as regiões de APPs de encostas. Apesar de não identificada APP de declividade, foi realizada a análise de frequência relativa das classes de declividade no município, segundo a classificação de relevo da EMBRAPA (EMBRAPA, 1999) (Tabela 2). A maior parte da região de estudo apresentou relevo entre plano $(59,43 \%)$ e ondulado $(22,46 \%)$, com algumas regiões com relevo de maior declividade e entre ondulado $(11,66 \%)$ e forte ondulado $(6,45 \%)$.

A área estudada não apresentou APPs de topo de morro, o que se deve ao fato de que, na Lei n. ${ }^{\circ}$ $12.651 / 12$, para a existência desse tipo de APP, deve-

Tabela 2. Variação relativa da declividade comparando com a classificação da Embrapa (1999).

Table 2. Relative variation of the slope based in the Embrapa's (1999) classification.

\begin{tabular}{|lcc|}
\hline $\begin{array}{c}\text { Classes de } \\
\text { declividade }\end{array}$ & $\begin{array}{c}\text { Declividade } \\
(\%)\end{array}$ & $\begin{array}{c}\text { Porcentagem (\%) } \\
\text { da declividade em } \\
\text { relação à área de } \\
\text { estudo }\end{array}$ \\
\hline Plano & $0-3$ & 59,43 \\
\hline Suave Ondulado & $3-8$ & 22,46 \\
\hline Ondulado & $8-20$ & 11,66 \\
\hline Forte Ondulado & $20-45$ & 6,45 \\
\hline Montanhoso & $45-75$ & 0,00 \\
\hline Escarpado & $>75$ & 0,00 \\
\hline
\end{tabular}

Fonte: Embrapa (1999). se concomitantemente haver elevações acima de $100 \mathrm{~m}$ e declividades superiores a $25^{\circ}$, que equivale em porcentagem a 46,63\% (Brasil, 2012). Conforme observado na Tabela 2, não ocorreram declividades superiores 45\%, apesar de existirem elevações superiores a $100 \mathrm{~m}$ (Figura 3).

A Tabela 3 mostra a contribuição de cada classe de APP representativa deste estudo. Após o mapeamento das APPs de hidrografia, constatouse que estas ocuparam uma área de 40,02 km², o que representou $15,01 \%$ do total da área de Seropédica (Tabela 3). A menor APP identificada no estudo foi a região dos lagos urbanos $\left(0,10 \mathrm{~km}^{2}\right.$ 0,04\%) (Figura 6c), enquanto a APP de maior representatividade foi a do Rio Guandu $\left(19,28 \mathrm{~km}^{2}\right.$ 7,23\%) (Figura 6a). Essa APP se destacou em virtude do Decreto 40.6270/07, que estabelece a criação da Área de Preservação Ambiental - APA Guandu (Rio de Janeiro, 2007). Os cursos de água menores do que $10 \mathrm{~m}$ apresentam área de $16,66 \mathrm{~km}^{2}$ e representaram 6,25\% da área do Município (Tabela 3).

Capitano (2008) realizou estudo para estabelecer áreas de servidão florestal no Campus da Universidade Federal Rural do Rio de Janeiro (UFRRJ), no município de Seropédica-RJ, e identificou $0,11 \mathrm{~km}^{2}$ de APPs de lagos. Os resultados obtidos neste estudo foram similares aos de Capitano (2008), o que se deve ao fato de o município possuir poucos lagos inseridos na sua área urbana e os existentes estarem localizados dentro da área do Campus da UFRRJ. A única diferença refere-se à metodologia aplicada (base de dados utilizados no mapeamento), pois na APP de lagos, Capitano (2008) utilizou um mosaico das imagens dos satélites IKONOS II e QUICKBIRD do ano de 2006, enquanto neste estudo considerouse a base cartográfica da década de 1970, na qual

Tabela 3. Variação relativa das APPs no total e representatividade no município.

Table 3. Relative variation at APP's total and municipal representation.

\begin{tabular}{lccc}
\multicolumn{1}{c}{ APPs } & Área $\left(\mathbf{k m}^{2}\right)$ & $\begin{array}{c}\text { Porcentagem (\%) da área em } \\
\text { relação à área total de APPs }\end{array}$ & $\begin{array}{c}\text { Porcentagem }(\%) \text { da área em } \\
\text { relação à área de estudo }\end{array}$ \\
\hline Lagos urbanos & 0,10 & 0,24 & 0,04 \\
Lagos rurais & 0,18 & 0,44 & 0,07 \\
Nascentes & 0,80 & 1,99 & 0,30 \\
Cursos d'água maior & 3,00 & 7,50 & 1,13 \\
Cursos d'água menor & 16,66 & 41,63 & 6,25 \\
Rio Guandu & 19,28 & 48,19 & 7,23 \\
\hline Total & $\mathbf{4 0 , 0 2}$ & $\mathbf{1 0 0 , 0 0}$ & $\mathbf{1 5 , 0 1}$ \\
\hline
\end{tabular}


determinadas feições do ambiente não existiam na época do mapeamento.

No mapeamento final, foram delimitadas $e$ quantificadas seis categorias de APPs (Figura 6). As categorias de APPs da rede hidrográfica e locação extensão do município foram bem caracterizadas através da metodologia adotada, sendo a APP do Rio Guandu a que apresentou maior extensão em relação às demais (Figura 6a). Através da Figura 6b, observou-se que a maioria das nascentes está posicionada nas direções sudoeste (SW) e noroeste (NW) de Seropédica. As categorias de APPs de lagos rurais e urbanos foram encontradas nos seguintes domínios: na região central e nas direções SW e NE de Seropédica (Figura 6c).

$\mathrm{O}$ índice Kappa estimado para imagem classificada utilizando o algoritmo da distância mínima apresentou acerto de 67,59\%, sendo esse valor considerado muito bom (Tabela 4 ).
$\mathrm{Na}$ classe pastagem, por exemplo, houve baixa uniformidade das amostras, ou seja, pixels considerados como solo exposto ou mata foram classificados como pastagem, criando assim uma confusão na classificação da imagem.

Após a classificação do uso da terra, foi feito o confronto das mesmas com as áreas de APPs, em que se observou que a maior parte das áreas de APPs, aproximadamente $65,30 \%$, encontrou-se como solo exposto (Tabela 5). Esse resultado evidenciou os conflitos de uso do solo atual do Município com a Legislação Ambiental vigente (Lei n. ${ }^{\circ}$ 12.651/12). Em contrapartida, a área destinada à areia/mineração correspondeu a 5,01\%, 5,20\% para áreas urbanas, enquanto a área coberta por pastagem representou cerca de 21,19\% da área total de APPs do município de Seropédica. Apenas 3,28\% das áreas identificadas como APP tinham cobertura de mata.

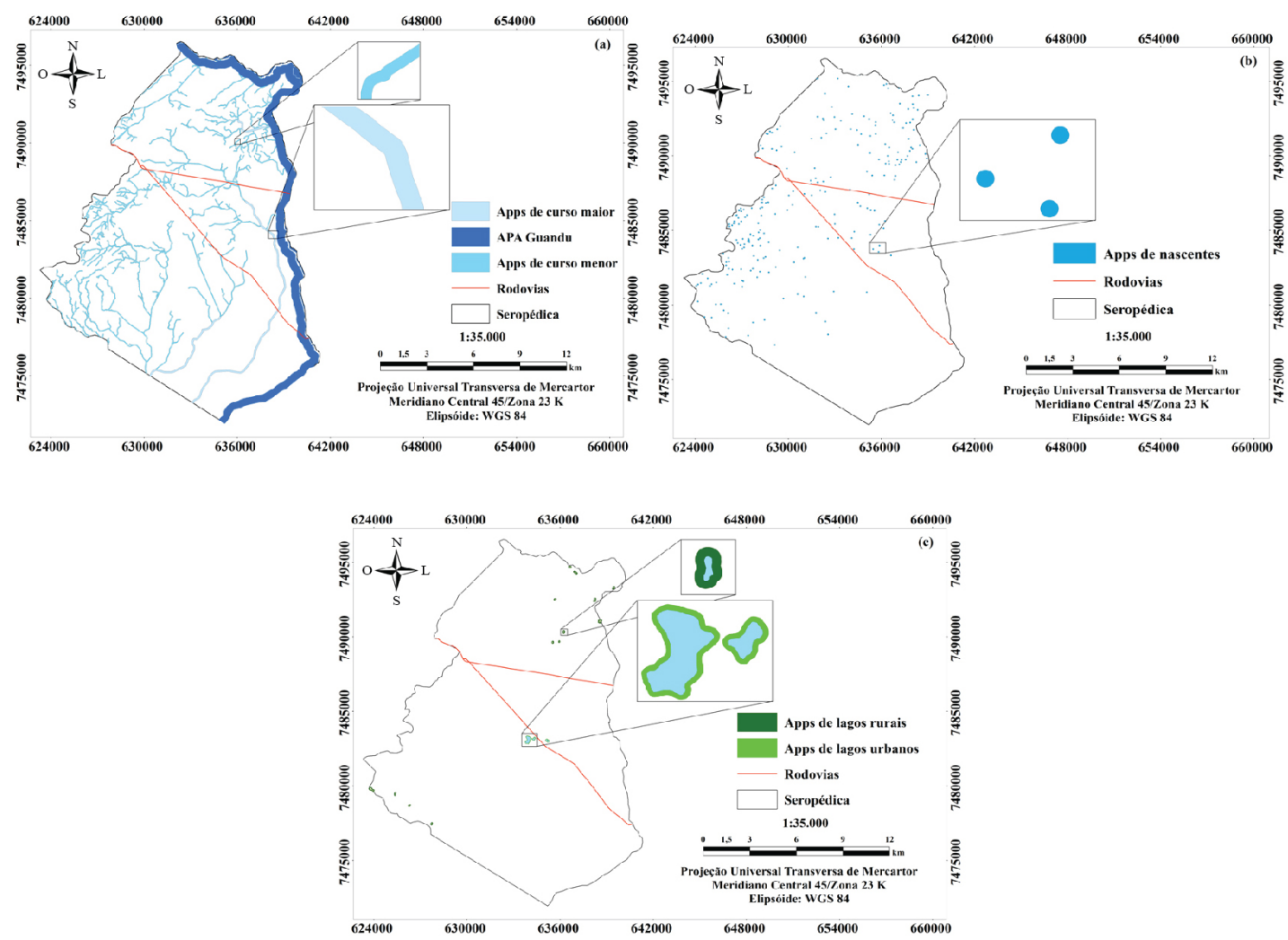

Figura 6. Mapeamento final das APPs de curso maior, curso menor e APA Guandu (a); APPs de nascente (b); APPs de Lagos Rurais e Urbanos (c), do município de Seropédica-RJ.

Figure 6. APP's higher and lower final course mapping and Guandu APA (a); APP's sunrise (b) Rural and Urban Lakes APP (c) at Seropédica, RJ municipal. 
Capitano (2008) encontrou na área do Campus da UFRRJ, em Seropédica, em torno de $87,4 \%$ de pastagem em áreas de APPs e $12 \%$ de remanescentes florestais em áreas de APPs. Salamene (2007), estudando as características ambientais da Área de Preservação Permanente do Rio Guandu, encontrou valores de $38,3 \%$ de pastagem na APP do Guandu, cerca de $17,7 \%$ de agricultura como uso, a classe de

Tabela 4. Resultados do índice Kappa da imagem classificada pelo algoritmo da mínima distância para Seropédica-RJ.

Table 4. Kappa coefficient from classified image by minimum distance algorithm for Seropédica, RJ.

\begin{tabular}{lcc}
\multicolumn{1}{c}{ Classes } & $\begin{array}{c}\text { Kappa } \\
\text { condicional }\end{array}$ & $\begin{array}{c}\text { Kappa } \\
\text { condicional (\%) }\end{array}$ \\
\hline Mata & 0,78 & 78 \\
Área urbana & 0,81 & 81 \\
\hline Solo exposto & 1,00 & 100 \\
\hline Pastagem & 0,73 & 73 \\
\hline Água & 1,00 & 100 \\
\hline Areia/Mineração & 1,00 & 100 \\
\hline Índice Kappa Global & & $\mathbf{6 7 , 5 9}$ \\
\hline
\end{tabular}

solo exposto com valor de 7,5\%, floresta com 7,4\% e capoeira em $4,2 \%$ do total da área que deveria ser APP. A Tabela 5 mostra a variação das porcentagens da ocupação do solo nas áreas de APPs. A Figura 7 apresenta o mapa de uso da terra; o Município mostrou áreas de mineração com razoável extensão na porção sul por se tratar de uma área de extração de areia para construção civil.

Tabela 5. Classes de uso do solo e suas correspondentes porcentagens em áreas de APPs.

Table 5. Classes of land use and their corresponding percentages in areas of APPs.

\begin{tabular}{lcc}
\multicolumn{1}{c}{ Classes } & Área $\left(\mathbf{k m}^{2}\right)$ & $\begin{array}{c}\text { Uso do solo em } \\
\text { área de APP (\%) }\end{array}$ \\
\hline Areia/Mineração & 23,81 & 5,01 \\
\hline Água & 2,17 & 0,02 \\
\hline Área Urbana & 19,38 & 5,20 \\
\hline Mata & 14,61 & 3,28 \\
\hline Pastagem & 86,59 & 21,19 \\
\hline Solo Exposto & 137,37 & 65,30 \\
\hline Total & $\mathbf{2 8 3 , 9 7}$ & $\mathbf{1 0 0 , 0 0}$ \\
\hline
\end{tabular}

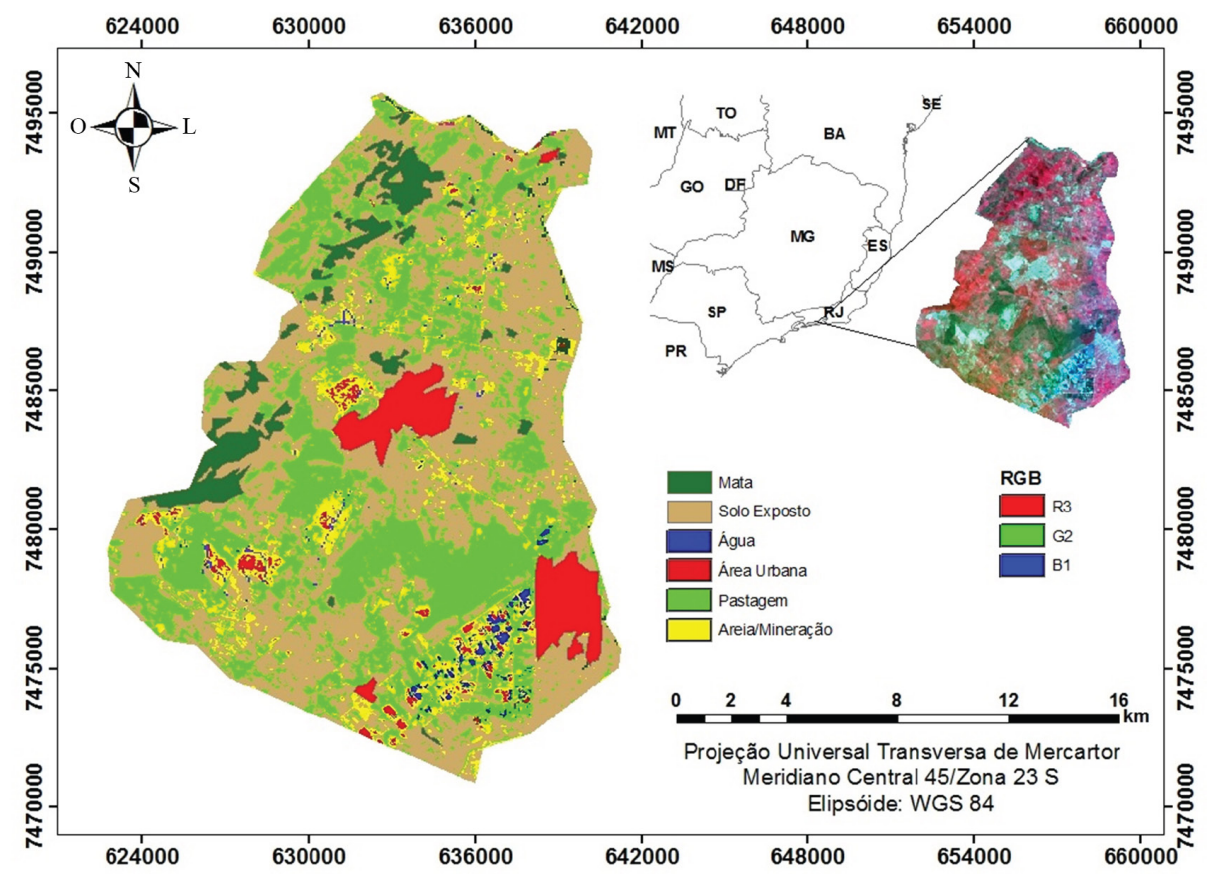

Figura 7. Classificação supervisionada do uso da terra utilizando o algoritmo da mínima distância e, no segundo plano, imagem da câmera CCD a bordo do satélite CBERS 2 com a composição RGB (3, 2 e 1) para Seropédica-RJ, para o período de 14/02/2008.

Figure 7. Supervised classification of land use using the algorithm of the minimum distance and the second plan, image of CCD camera onboard the satellite CBERS 2 with RGB composition $(3,2$ and 1$)$ to Seropédica-RJ, for the period of 02/14/2008. 


\section{CONCLUSÕES}

O município de Seropédica-RJ apresenta 40,02 $\mathrm{km}^{2}$ de área caracterizada como Área de Preservação Permanente (APP), segundo a Legislação Ambiental (Lei $\left.n^{\circ} 12.651 / 12\right)$, que corresponde a 15,01\% da área total do município (Brasil, 2012). A APP do Rio Guandu é a que apresenta a maior parte de área das APPs totais e representa 7,23\% da área do município. O município não apresenta APPs de declividade e de topo de morro em razão do seu relevo e da resolução dos dados utilizados para as análises.

O índice Kappa calculado com as áreas observadas (areia/mineração, mata, água, solo exposto, pastagem e área urbana), para imagem classificada utilizando o algoritmo da mínima distância, obteve bom desempenho.

A maior parte dos conflitos do uso do solo no município de Seropédica é decorrente da ocupação de áreas classificadas como APP com solo exposto $(65,30 \%)$, pastagem $(21,19 \%)$ e areia/mineração $(5,01 \%)$.

O uso de geotecnologias é eficiente na gestão municipal no que tange ao cumprimento das leis e como subsídio para otimizar o uso e a ocupação do solo do município de Seropédica-RJ. Ressalta-se que uma base de dados homogêneos e consistentes ajudará na obtenção de melhores resultados.

\section{AGRADECIMENTOS}

Os autores agradecem ao Instituto Brasileiro de Geografia e Estatística - IBGE e ao Centro Estadual de Estatísticas, Pesquisas e Formação de Servidores Públicos do Rio de Janeiro - CEPERJ, por disponibilizarem os dados de hidrografia e relevo, e ao Instituto Nacional de Pesquisas Espaciais - INPE, por ceder gentilmente as imagens do satélite CBERS 2.

\section{STATUS DA SUBMISSÃO}

Recebido: 05/09/2012

Aceito: 14/08/2013

Publicado: 30/09/2013

\section{AUTOR(ES) PARA CORRESPONDÊNCIA}

\section{Gustavo Bastos Lyra}

Departamento de Ciências Ambientais, Universidade Federal Rural do Rio de Janeiro - UFRRJ, Rod. BR 465, Km 7, CEP 23890-970 Seropédica, RJ, Brasil

e-mail: gblyra@gmail.com

\section{REFERENNCIAS}

Binder W. Rios e Córregos, Preservar - Conservar Renaturalizar: A Recuperação de Rios, Possibilidades e Limites da Engenharia Ambiental. Rio de Janeiro: Secretaria de Estado de Meio Ambiente e Desenvolvimento Sustentável - (SEMADS); 1998. 41 p.

Brasil. Lei no 12.651, de 25 de maio de 2012. Dispõe sobre a proteção da vegetação nativa; altera as Leis nos 6.938, de 31 de agosto de 1981, 9.393, de 19 de dezembro de 1996, e 11.428, de 22 de dezembro de 2006; revoga as Leis nos 4.771, de 15 de setembro de 1965, e 7.754, de 14 de abril de 1989, e a Medida Provisória no 2.166-67, de 24 de agosto de 2001; e dá outras providências. Diário Oficial da República Federativa do Brasil, Brasília, DF (2012 out. 17)

Brasil. Lei no 4.771 . de 15 de setembro de 1965. Código Florestal. Diário Oficial da República Federativa do Brasil, Brasília, DF (1965 set. 16).

Caldas AJFS. Geoprocessamento e análise ambiental para determinação de corredores de hábitat na Serra da Concórdia, Vale do Paraíba - RJ [dissertação] Seropédica: Instituto de Florestas, Universidade Federal Rural do Rio de Janeiro; 2006.

Capitano RC. Proposta de Delimitação da Reserva Legal e Implantação de área de Servidão Florestal no Campus da Universidade Federal Rural do Rio de Janeiro [monografia]. Seropédica: Instituto de Florestas, Universidade Federal Rural do Rio de Janeiro; 2008.

Embrapa. Centro Nacional de Pesquisa de Solos. Sistema Brasileiro de Classificação de Solos. Brasília: Embrapa; 1999. 412 p.

Instituto Brasileiro de Geografia e Estatística - IBGE. Geociências. [cited 2011 set. 10]. Available from: www. ibge.gov.br/geociencias/default_prod.shtm\#TOPO.

Jaccoud CFS. Produção de Biomassa de Eucalyptus Urophylla em Três Classes de Solos em Seropédica, $R J$ [monografia]. Seropédica: Instituto de Florestas, Universidade Federal Rural do Rio de Janeiro; 2006.

Lima A. Instrumentos para a conservação da diversidade biológica: o Zoneamento Ecológico-Econômico, as unidades de conservação, o Código Florestal e o sistema de recursos hídricos. 2. ed. BENSUSAN; 2008. 
Moreira MA. Fundamentos do sensoriamento remoto e metodologias de aplicações. São Jose dos Campos: INPE; 2001.

Nascimento CM, Soares VP, Ribeiro CAAS, Silva E. Delimitação automática de Áreas de Preservação Permanente (APP) e identificação de conflito de uso da terra na bacia hidrográfica do rio Alegre. In: Anais do XII Simpósio Brasileiro de Sensoriamento Remoto; 2005; Goiânia. INPE; 2005. p. 2289-2296.

Peluzio TMO, Santos AR, Fieldler NC. Mapeamento de áreas de preservação permanente no ARCGIS 9.3. Alegre: CAUFES; 2010. 58 p.

Piroli EL, Becker ELS, Bolfe EL. Análise do uso da terra na microbacia do Arroio do Meio - Santa MariaRS, por sistema de informações geográficas e imagens de satélite. Ciência Rural 2002; 32(3): 407-413. http:// dx.doi.org/10.1590/S0103-84782002000300007

Quintero EI, Pereira M, Francelino M. Influência da Escala do MDE na Delimitação da Classes de Declividade. In: Anais do XVII Encontro Brasileiro de Manejo e Conservação do Solo e da Água; 2008; Rio de Janeiro. Rio de Janeiro; 2008.

Ribeiro CAAS, Soares VP, Oliveira AMS, Gleriani JM. O desafio da delimitação de Áreas de Preservação Permanente. Revista Árvore 2005; 29(2): 203-212. http://dx.doi.org/10.1590/S0100-67622005000200004
Rio de Janeiro (Estado). Secretaria de Estado de Meio Ambiente e Desenvolvimento Sustentável - SEMADS. Bacias Hidrográficas e Recursos Hídricos da Macrorregião Ambiental 2 - Bacia da Baía de Sepetiba. Rio de Janeiro: SEMADS; 2001.79 p.

Rio de Janeiro (Estado). Decreto $\mathrm{n}^{\circ}$ 40.6270, $22 \mathrm{de}$ março de 2007. Dispõe sobre a criação da Área de Proteção Ambiental do rio Guandu (APA Guandu) e outras providências. Diário Oficial do Estado do Rio de Janeiro, Brasília, DF (2007 mar.).

Salamene S. Estratificação e Caracterização Ambiental da Área de Preservação Permanente do rio Guandu, $R J$ [dissertação]. Seropédica: Instituto de Florestas, Universidade Federal Rural do Rio de Janeiro; 2007.

Soares VP, Moreira AA, Ribeiro CAAS, Gleriani JM, Gripp J Jr. Mapeamento de Áreas de Preservação Permanentes e Identificação dos Conflitos Legais de Uso da Terra na Bacia Hidrográfica do Ribeirão São Bartolomeu - MG. Revista Árvore 2011; 35(3): 555-563. http://dx.doi.org/10.1590/S0100-67622011000300018

Valente OF, Gomes MA. Conservação de nascentes: hidrografia e manejo debacias hidrográficas de cabeceiras. Viçosa: Aprenda Fácil; 2005.

Xavier-da-Silva J. Geoprocessamento para análise ambiental. Rio de Janeiro: Ed. Jorge Xavier da Silva; 2001. 